\title{
OPTIMIZATION OF DIMENSION AND SHAPE FOR BALL VALVE BODY IN FIRE SAFE DESIGN
}

\author{
GHEORGHIŢA TOMESCU ${ }^{*}$, RADU IATAN ${ }^{2}$, IULIANA IAŞINICU (STAMATE) ${ }^{3}$ \\ ${ }^{1}$ S.C. UPET S.A., Arsenalului Street, no.14, Targoviste130021 Romania \\ ${ }^{2}$ Department of Industrial Process Equipment, University Politehnica of Bucharest, Splaiul \\ Independentei no. 313, Bucharest 060042, Romania \\ ${ }^{3}$ Technical College Gheorghe Asachi, Aleea Pravăț, no. 2, Bucharest 061566, \\ Romania
}

\begin{abstract}
The fire safe valves are designed for petroleum and petrochemical complexes and allied industries because working fluid characteristics result in a high fire risk, detonation and / or explosion. Fire Safe Certification is achieved through a standardized fire testing. This article aims to show how to optimize the shape and size of the main body of a ball valve in sequence CAD - FEM - testing and evaluation of the performance of valves when exposed to fire. This analysis is necessary because fire testing is expensive to verify and the validation of constructive solutions helps reduce production costs and achieve fire prevention through design.
\end{abstract}

Keywords: fire safe valve, optimization, FEM

\section{INTRODUCTION}

Fire-safe valves play an important role in reducing losses due to accidental fires (financial, human and environmental). Their use can isolate fault portions of the equipment and process from the rest of the plant, power failure with flammable products in the exposed area of the fire [1], and errors in choosing valves or absence fire-safe feature can have catastrophic consequences [2].

This type of valve satisfies main trends manifested in the construction and use of such equipment: small dimensions, low-pressure losses, use self-sealing (adjustable as contact pressure and the relative position of the obturator against the sealing surface of the body). Add to this double sealing: nonmetal/metal to ensure closing in case of the existence of the gaseous component in working fluid and metal/metal for the situation of the first metallic sealing element destruction due to fire.

\section{DESIGN OF THE MAIN BODY OF THE VALVE}

\subsection{Establishing parts shape and predimensioning}

Determination of a valve body shape is generally subject to the conditions of flow of the fluid and the mounting of the closure element.

\footnotetext{
* Corresponding author, email: tomescu.gb@gmail.com

(C) 2015 Alma Mater Publishing House
} 
To calculate such a body is necessary to proceed to divide it into portions with regular geometric shapes: spherical, cylindrical or flat to allow the use of simple relationships that are based computing, in general membrane theory, the theory of moments bending or body with thick walls theory [3 $\div 5]$. In bonding areas, Valve bodies are provided with crossings connected and complicated bending shapes. Most often, there are set technological reasons, or they depend on experienced designer.

Optimizing body shape and dimensions (and other parts) can be achieved using computer-aided design (CAD) in the finite element method (FEM). FEM is an important part of the process of designing the equipment. In succession CAD-FEM-experimental tests there is an iterative process: design - calculation -manufacturing (Figure 1).

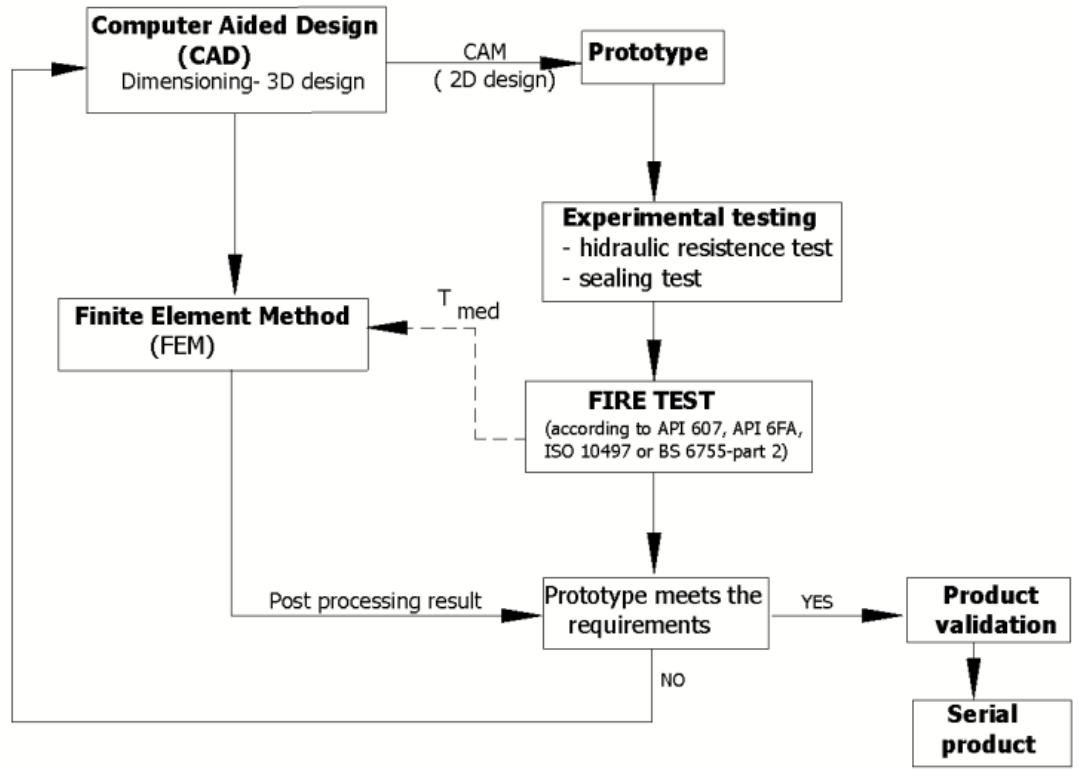

Fig. 1. The main components of an optimized system design.

Thus, in parallel with the design, modeling and finite element analysis of parts and / or assembly the prototype is subjected to the running of tests (in this case the attempt to hydraulic resistance, sealing and fire safety). Such optimization was done in the case of floating ball valve design in fire safe construction NPS 4 "(100 mm), class 300 (NP 50).

Valve design assumes (after beneficiary requirements analysis, determining the functional and technical characteristics) framing in the required dimensions of the product standard (in this case, API 6A), the calculation simple forms valve and modeling valves (Figure 2).

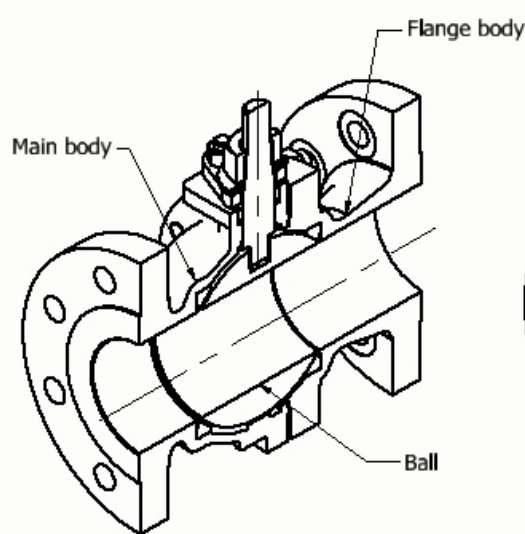

a.

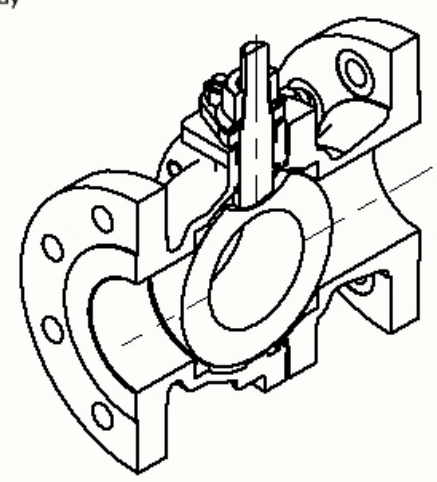

b.

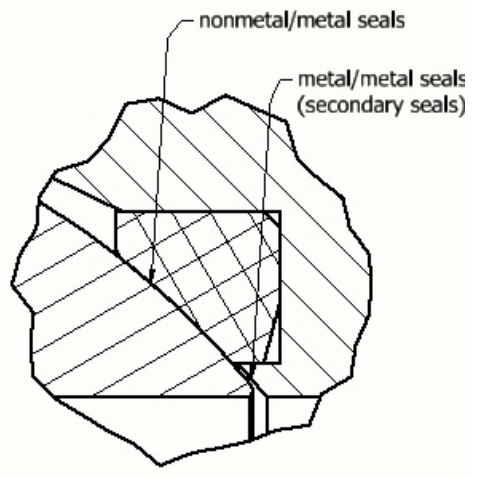

c.

Fig. 2. Fire-safe ball valve: a. open valve; b. close valve; c. Double seals (nonmetal $/ \mathrm{metal}$ and metal/metal). 


\subsection{Experimental testing and fire test of prototype}

The prototype executed is checked from the point of view of the hydraulic resistance (at a pressure of 55 bar $=$ $1.1 \mathrm{xNP}$ with water) and the sealing (with air at 5.5 bar).

The fire-safe test shall be made in a stand that meets the requirements of API 607 standard [6]. In the testing stand, the valve, with the obturator in closed position, is pressurized and burned for 30 minutes (Figures 3 a and b). It is subjected to the action of four burner flames oriented equipment. Flame temperature is controlled by thermocouples and temperature calorimeter through the valve body of near cubes placed in the positions indicated by the standard.

Validation of the test is made if the conditions imposed by the API specification: maintain the pressure in the system at specified value, the average temperature of $650^{\circ} \mathrm{C}$ cubes calorimetric - at 15 minutes after ignition and flame average temperature of $760^{\circ} \mathrm{C}$ at $2 \mathrm{~min}$ from same moment. The valve is fire-safe if the maximum allowable through valve seat leakage is within the requirements limits of the applied standard $[7,8]$.

A total of four tests to fire were made on this type of valve. That has enabled a series of observations on the effect of burning on the seals surfaces, on the damage of the quality of the parts and influence the surface quality has on the valve functionality.

For testing with FEM, temperatures on the exterior of the object were measured, immediately after the fire.The points in which was measured temperature are indicated in Figure 4 and the average temperatures measured are indicated in Table 1.

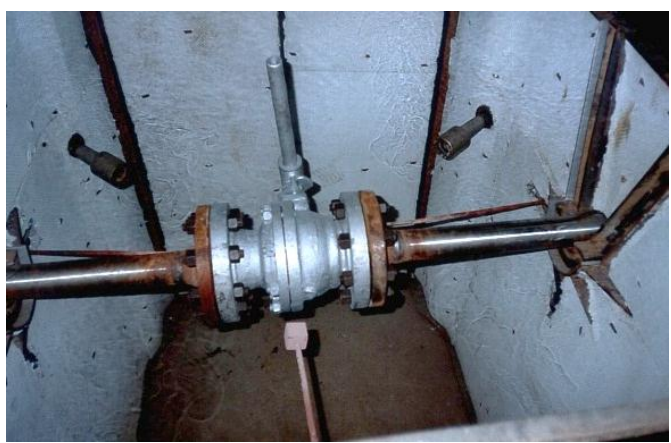

a

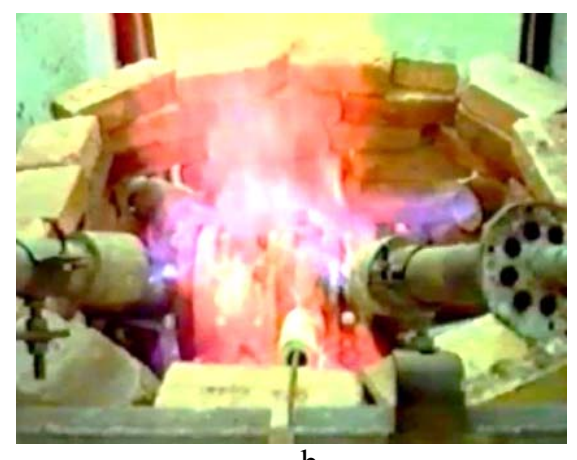

b

Fig. 3. The valve prototype attempted to fire: a. installation of temperature measurement sensors; b. burning the valve.

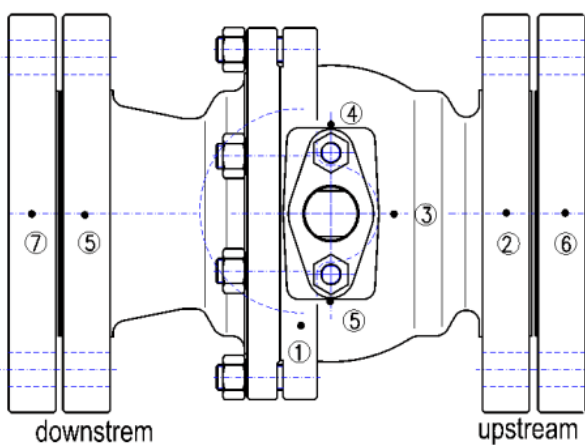

Fig. 4. The points in which was measured temperature after the fire, at the time when the burners were extinguished.

Table 1. The average temperatures measured after the fire, at the time when the burners were extinguished.

\begin{tabular}{|c|c|c|c|c|c|c|c|}
\hline $\begin{array}{c}\text { Point } \\
\text { measurement }\end{array}$ & 1 & 2 & 3 & 4 & 5 & 6 & 7 \\
\hline $\begin{array}{c}\text { Medium } \\
\text { temperature, }{ }^{\circ} \mathrm{C}\end{array}$ & 471 & 408 & 437 & 464 & 419 & 392 & 471 \\
\hline
\end{tabular}




\subsection{Finite element analysis}

Current conditions require material and energy cost optimization in design and operation of such equipment, with the guarantee of complete safety during use, throughout the equipment life. Thus, it is necessary to develop rapid methods of calculation, accurate, verified and confirmed experimentally.

\subsubsection{The proposed analytical method}

Calculation of resistance to bending moments using shells theory of revolution is a classical method for calculating the resistance of the valves bodies.

The body of a ball valve can be decomposed into three types of shells of revolution: a cylindrical portion with horizontal axis, a vertical cylindrical zone axis and a spherical asymmetrical area (Figures $5 \mathrm{a}, \mathrm{b}$ and c).

For each component, the equilibrium differential equations of the theory of bending moments are determined [9]. This approach leads to determining a number of partial differential equations in which the unknowns are internal efforts and deformations. Solving the system can be done by finite difference method that consists of the partition to the domain of definition and replacing the differential expressions with expressions approximated by differences.

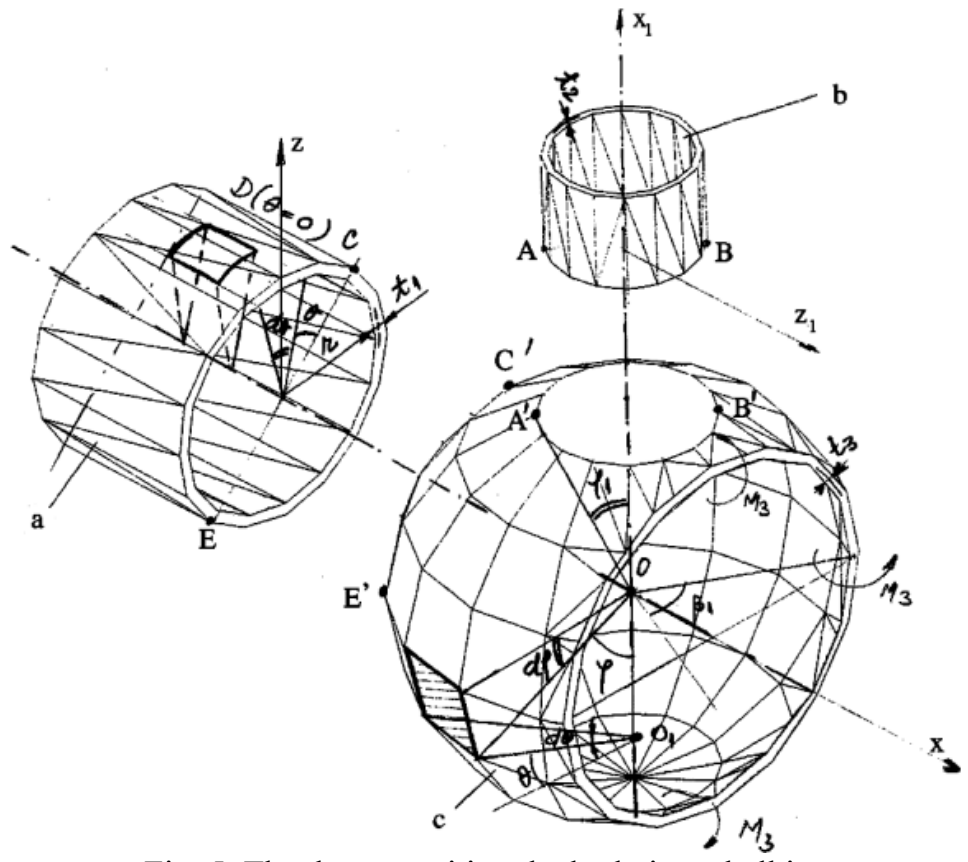

Fig. 5. The decomposition the body into shell items.

For the solution, a software that is based on the following algorithm may be used:

- decomposing the assemblies in simple structures (cylindrical and spherical shells);

- the writing of the differential equations of equilibrium for these assemblies using theory with bending moments for shells;

- expressing the differential equations of equilibrium for these subassemblies, according to displacements;

- decomposition in Fourier series of external loads and displacements;

- expression of differential equations equilibrium for these subassemblies depending to a single variable;

- solving these differential equations using finite differences;

- determination of the sectional displacements and efforts.

Disadvantages of the method:

- it does not take into account the uneven wall thickness, for certain areas;

- it ignores the existence of connecting flanges, by the anisotropy introduced by welded joints, by the residual stresses from the welding seams, etc.;

- it does not take into account the additional loads due to mounting, by the dilatations that may occur during operation, thermal dilatations and the additional load due to the obturator driving. 


\subsubsection{The finite element analysis as a verification and improvement method of the design}

Finite element analysis (using various specialized software) allows assessment of equivalent stresses and displacements on a meshed structure. It has the advantage of allowing their assessment considering the variation in the body temperature, by the pressures from the system and all loads from the valve assembly.

In the case of these valves, eight studies on the body were analyzed (using SolidWorks). In Study 1 requests caused by working fluid pressure and loads by assembly and sealing were taken into account (Figures 6 a, b, Figures $7 \mathrm{a}, \mathrm{b}$ and Table 2).

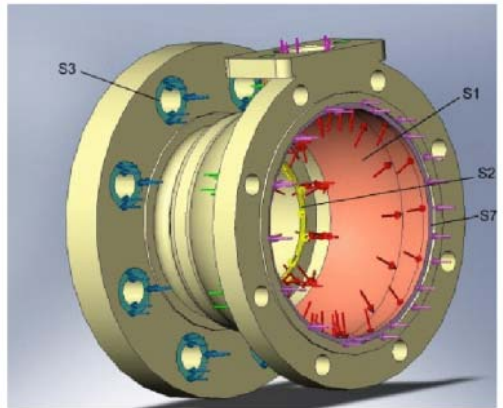

a

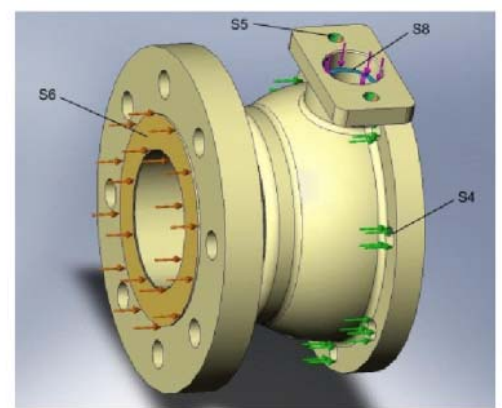

b

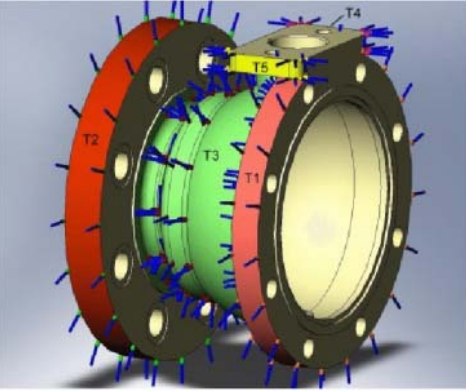

C

Fig. 6. a, b. Positioning the surfaces which that apply loads (according to Table 2); c. surfaces which are applied temperatures (according to Table 3 ).

Studies 2, 3, 4 and 5 were made using the 4 series of actual measured temperatures during the test (Figure 6c and Table 3), after which, for study 6, 7 and 8 have been amended certain values of its. This has been designed so that it is possible to form an image on the behavior of the body, temperature zones that significantly influence results and what happens to high temperatures, simulating the fires with 30 minutes longer considered major events with consequences that can not be evaluated by this test (study 6, 7 and 8).

Table 2. Study 1- Types of loads and surfaces which that acts.

\begin{tabular}{|c|c|c|c|}
\hline \multicolumn{4}{|r|}{ Load } \\
\hline & Surface & Load & Note \\
\hline $\begin{array}{l}\text { Pressure } 1 \\
\quad(\mathrm{P} 1)\end{array}$ & S1 & $5.1 \mathrm{~N} / \mathrm{m}^{2}$ & $\begin{array}{l}\text { Internal pressure according to hydraulic resistance test (740 } \\
\text { psi }=5.1 \mathrm{MPa})\end{array}$ \\
\hline $\begin{array}{l}\text { Pressure } 2 \\
(\mathrm{P} 2)\end{array}$ & S2 & $3.281 \mathrm{~N} / \mathrm{m}^{2}$ & $\begin{array}{l}\text { The necessary pressure on the sealing ring, in the absence of non- } \\
\text { metallic ring }\end{array}$ \\
\hline Force $1(\mathrm{~F} 1)$ & $8 \times \mathrm{S} 3$ & $50538 \mathrm{~N}$ & $\begin{array}{l}\text { The force given by fasteners of connecting main body - conduit } \\
\text { flange }\end{array}$ \\
\hline Force $2(\mathrm{~F} 2)$ & $8 \times \mathrm{S} 4$ & $32157 \mathrm{~N}$ & $\begin{array}{l}\text { The force given by fasteners of connecting main body } 1 \text { - flange } \\
\text { body }\end{array}$ \\
\hline Force $4(\mathrm{~F} 4)$ & $2 \times \mathrm{S} 5$ & $1100 \mathrm{~N}$ & The force given by fasteners for tightness in stuffing box \\
\hline Force $5(\mathrm{~F} 5)$ & S6 & $92750 \mathrm{~N}$ & $\begin{array}{l}\text { The force required to ensure the sealing gasket main body-the pipe } \\
\text { flange connection }\end{array}$ \\
\hline Force $6(\mathrm{~F} 6)$ & S7 & $31642 \mathrm{~N}$ & $\begin{array}{l}\text { The force required to ensure the sealing gasket main body } 1 \text { - } \\
\text { flange body }\end{array}$ \\
\hline Force 7 (F7) & S8 & $2000 \mathrm{~N}$ & The force required to ensure the sealing gasket from stuffing box \\
\hline
\end{tabular}

Table 3. Loads and temperatures which is applied in studies 1-8.

\begin{tabular}{|c|c|c|c|c|c|c|}
\hline \multirow[t]{2}{*}{ Study } & \multirow[t]{2}{*}{ Load } & T1 & $\mathrm{T} 2$ & T3 & $\mathrm{T} 4$ & $\mathrm{~T} 5$ \\
\hline & & \multicolumn{5}{|c|}{$\left({ }^{\circ} \mathrm{C}\right)$} \\
\hline Study 1 (hydraulic resistance test) & \multirow{8}{*}{$\begin{array}{l}\text { P1 } \\
\text { P2 } \\
\text { F1 } \\
\text { F2 } \\
\text { F4 } \\
\text { F5 } \\
\text { F6 } \\
\text { F7 }\end{array}$} & \multicolumn{5}{|c|}{22} \\
\hline Study 2 (Fire test no.1) & & 450 & 362 & 415 & 415 & 340 \\
\hline Study 3 (Fire test no.2) & & 478 & 410 & 452 & 462 & 388 \\
\hline Study 4 (Fire test no.3) & & 490 & 432 & 440 & 492 & 476 \\
\hline Study 5 (Fire test no.4) & & 488 & 428 & 451 & 486 & 474 \\
\hline Study 6 & & 488 & 428 & 565 & 486 & 474 \\
\hline Study 7 & & 565 & 565 & 565 & 565 & 565 \\
\hline Study 8 (simulating the fires with 30 minute & & 760 & 760 & 760 & 760 & 760 \\
\hline
\end{tabular}


The meshing structure was made with solid finite elements, tetrahedral with curved edges. The material (ASTM A 216 WCB) was defined by the variable mechanical properties with tempera ture (Yield strength, elastic modulus and thermal expansion coefficient).

\section{CONCLUSIONS ON THE EXPERIMENTAL RESULTS AND THE THEORETICAL ANALYSIS}

The temperatures measured on the outside of the valve body do not reach the required value of calorimeters (cubes). These values can not be assigned to a particular schema or model because they are dependent on subjective conditions (methane gas pressure and its quality; burners orientation etc.)

The study 1 results indicate low Von Mises tension (132 MPa) and the displacement (max. $0.018 \mathrm{~mm})$ values in the valve body (Figures $7 \mathrm{a}$ and $\mathrm{b}$ ).

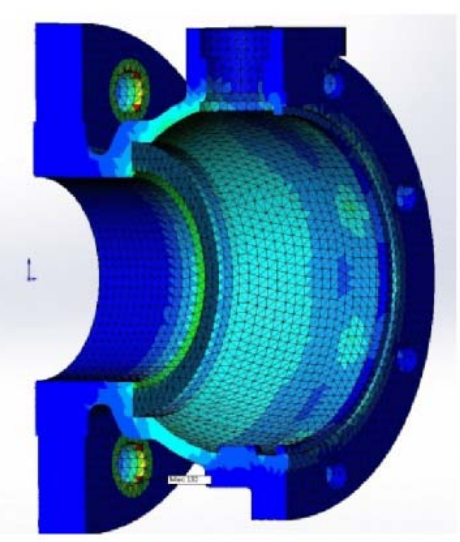

a

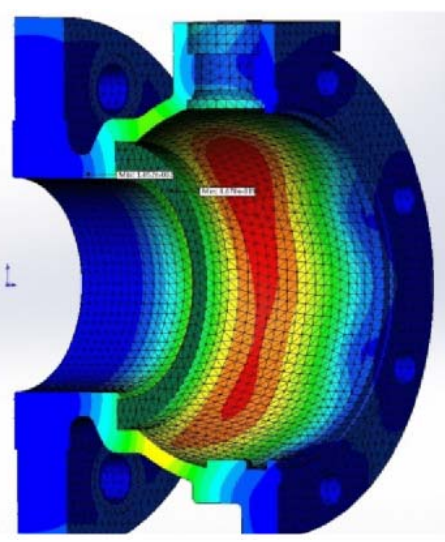

b

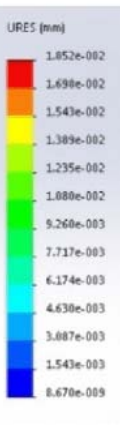

Fig. 7. The results of finite element analysis: a. Static vonMises stress [MPa] (Study 1); b. Displacement [mm] (Study1).

The area of interest from the viewpoint of the seal is the machined ring in the body of the valve (Figure $2 \mathrm{c}$ ). 36 nodes were selected on the half outer edge of the metal seal ring and the equivalent stress (von Mises) and displacement values were measured for nodes located along the edges (from 0 to $\pi$ ). The values for each parameter have been displayed as a graphic (Figures $8 \mathrm{a}$ and $\mathrm{b}$ ).

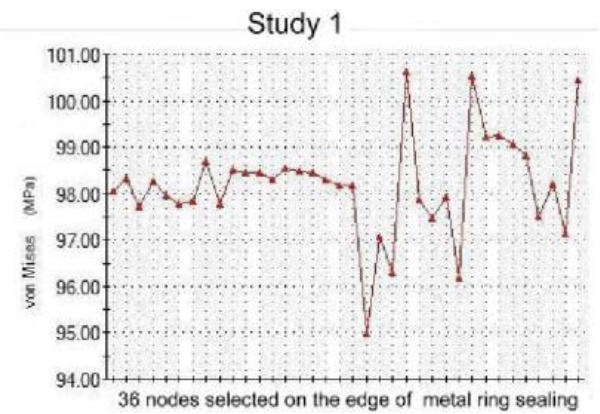

a.

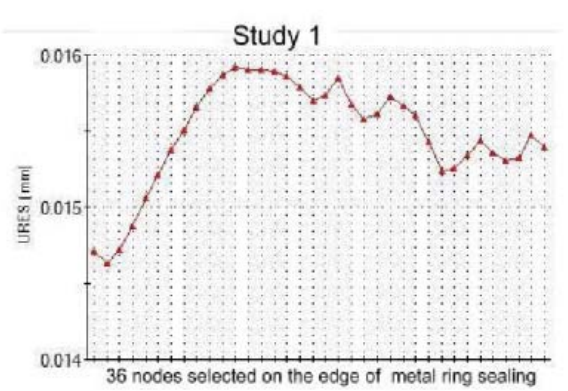

b.

Fig. 8.: a. Static vonMises stress [MPa] (Study 1); b. Displacement [mm] (Study1), on 36 nodes selected on the edge of metal ring sealing.

When the imposed temperature of the outer surface of the body is close to $400^{\circ} \mathrm{C}$ the main stress in the sealing ring $(178 \mathrm{MPa})$ approaches the yield strength of the material at this temperature $(180 \mathrm{MPa})$, the maximum (186 MPa- Study 2) near the plane containing the pivot axis of the drive of the sphere (Figure 9 a and Figure 9 b). 
Nodal displacements, on the seal ring body are larger $(0.047 \mathrm{~mm})$ to the bottom, opposite the drive stem, while the nodal displacements of sphere seals in the area are much lower $(0.003 \mathrm{~mm})$, because the influence of the mounting of the obturator.

In test no. 1 the larger external losses were determined, in particular by targeting burners on fasteners, which has produced their lengthening. Simultaneously were noted: loss of tightness between the parties and between the valve body and connecting flanges, a decrease in the internal pressure and the penetration of molten material of non-metallic rings between the sealing surfaces.

The temperature that significantly influences the valve body and the stresses and deformations is spherical body temperature. This was determined at study 6 versus study 5, where the temperature T3 was increased from $441^{\circ} \mathrm{C}$ to $565^{\circ} \mathrm{C}$. This change determined an increase of $20 \%$ of stress in study 6 compared to study 5 . In the study 7 , temperature increase on all surfaces at $565^{\circ} \mathrm{C}$ did not influence the behavior of the body in the sealing ring area.

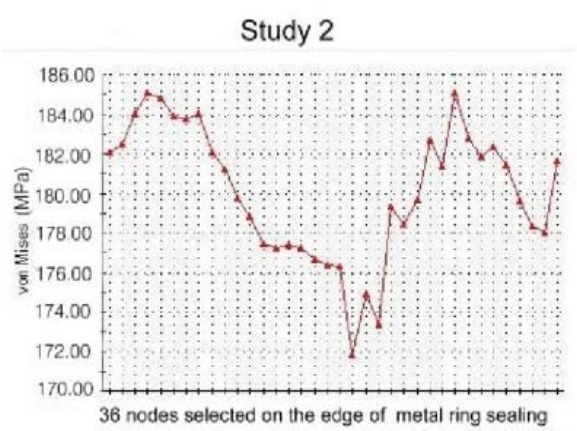

a

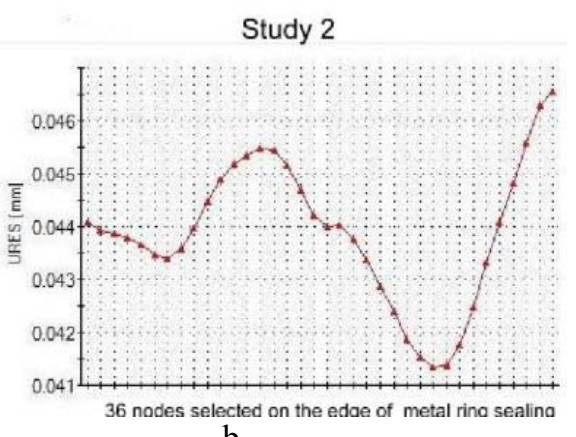

b

Fig. 9.: a. Static vonMises stress [MPa] (Study 2); b. Displacement [mm] (Study 2), on 36 nodes selected on the edge of metal ring sealing.

Once the temperature rose above the value $\left(565^{\circ} \mathrm{C}\right)$ the fact that the von Mises equivalent stress increase above the material yield stress can be seen. The significant displacement of the spherical valve body $(0.11 \mathrm{~mm})$, which can cause irreparable damage its (permanent deformation), is added to this.

By studying with finite element the behavior of valve body it can be noted that due to the small length of the body connection, equivalent stresses and displacements are influenced by elements of the main body assembly body flange or flange connection with the pipeline.

Depending on valve position in the installation area measures can be taken in order to protect the spherical body with an insulating material to prevent increased body temperature for a time period. Also, to preserve the sealing we can take the measure of controlled tightening of fasteners, so this values to influence least possible stresses and strains the body.

Making the prototype and correlation of experimental data with the results of finite element analysis allowed correcting deficiencies in design and manufacturing. The difference between the classic ball and the optimized one are: the valve body is modified by increasing the radius of connection of cylindrical area with the spherical area, resizing of sealing metal ring into the body valve, ring size above the stem collar correlated with arrow tensioners of disc springs, replacement materials for seals (graphite ring for steam saling and PTFE for nonmetallinc seat).

Is modify the finish of the stem's surface to be no more than Ra 0.8 and the surface of stuffing box is controlled to be $\mathrm{Ra} 3.2$. In this case, the graphite ring works as a lubricant to reduce stem torque and eliminate the leakage at the fire-safe test.

Making finite element studies in the design phase of the valve may have the effect of reducing costs with further testing, as the proposed constructive solutions, selected materials and components valve sizes can be verified. 


\section{REFERENCES}

[1] Pavel, A, Sources and Risk of damage to petroleum - petrochemicals and chemicals industry, UPG Ploieşti, 1993.

[2] Huitt, W.M., Piping Design for Hazardous Fluids, Chemical Engineering magazine, October 2010, www.wmhuittco.com (25.09.2015).

[3] Renert, M., Calculation and construction of chemical equipment, Part 1, Didactic and Pedagogical Publisher, Bucharest, 1974.

[4] Pavel, A., Elements of Mechanical Engineering, Didactic and Pedagogical Publisher, Bucharest, 1982.

[5] Pradip, B.P., Gambhire, V.R., Structural Analysis of gate valve body using FEA, International Journal of Engineering Research\&Technology, vol. 3, no. 6, 2014.

[6] API 607 - Fire Test for Soft-Seated Quarter-Turn Valves.

[7] Tomescu, Gh., Oncescu, L., Comparative study of main standards concerning to fire test of valves.

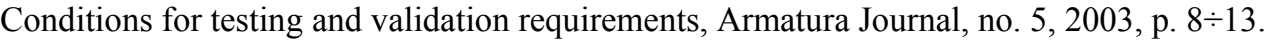

[8] Tomescu, Gh., Oncescu, L., Fire test of valve. Standard, testing conditions, validation and experimental

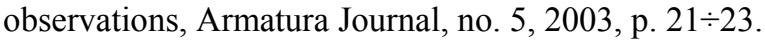

[9] Tomescu, Gh., Analytical and numerical methods for calculating the resistance of ball valve bodies, Part I,

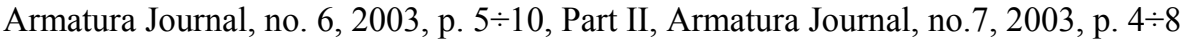

